\title{
Four sociologies, multiple roles
}

\author{
Stella R. Quah
}

The current American and British debate on public sociology introduced by Michael Burawoy in his 2004 ASA Presidential Address (Burawoy 2005) has inadvertently brought to light once again, one exciting but often overlooked aspect of our discipline: its geographical breadth. ${ }^{1}$ Sociology is present today in more countries around the world than ever before. Just as in the case of North America and Europe, Sociology's presence in the rest of the world is manifested in many ways but primarily through the scholarly and policyrelevant work of research institutes, academic departments and schools in universities; through the training of new generations of sociologists in universities; and through the work of individual sociologists in the private sector or the civil service.

Michael Burawoy makes an important appeal for public sociology 'not to be left out in the cold but brought into the framework of our discipline' (2005: 4). It is the geographical breadth of Sociology that provides us with a unique vantage point to discuss his appeal critically. And, naturally, it is the geographical breadth of sociology that makes Burawoy's Presidential Address to the American Sociological Association relevant to sociologists outside the USA.

\section{Ideas relevant to all sociologists}

What has Michael Burawoy proposed that is most relevant to sociologists beyond the USA? He covers such an impressive range of aspects of the discipline that it is not possible to address all of them here. Thus, thinking in terms of what resonates most for sociologists in different locations throughout the geographical breadth of the discipline, I believe his analytical approach and his call for integration deserve special attention.

In his wide-ranging and detailed article, Burawoy examines sociology as a discipline with four dimensions or ideal types - professional, policy, public and 
critical - guided by the questions 'Sociology for what?' and 'Sociology for whom?' following Lee (1976) and Lynd (1939). He recognizes the complexity of each type and the vital interrelation across all four sociologies and correctly identifies professional sociology as 'the sine qua non' of policy and public sociologies (Burawoy 2005: 10) as well as of critical sociology. In his words, 'At the heart of our discipline is its professional component. Without professional sociology, there can be no policy or public sociology, but nor can there be a critical sociology - for there would be nothing to criticize' (2005: 15). This is a very insightful approach mainly because it is comprehensive and facilitates the identification of significant ways of practising Sociology as a unified discipline.

More importantly, Burawoy calls for integration and complementarity in all sociological labour: not only between traditional and organic public sociology (2005: 7-8), but also as a fundamental principle for the entire discipline: 'The flourishing of our discipline depends upon a shared ethos, underpinning the reciprocal interdependence of professional, policy, public, and critical sociologies' (2005: 15).

These are, in my opinion, the two aspects of Burawoy's article that are most important for sociologists everywhere. While the advance of sociological knowledge depends on a constant and constructive debate of ideas on theory and methodology, the fragmentation and convolution of our discipline have been causes of concern for the past three decades (Ritzer 1975, 1990; Wiley 1990; Smelser 1998). Michael Burawoy reminds us to examine for whom and for what are we doing sociology, and he offers a framework of the four areas of work within which we should contribute to the growth of the entire discipline in the spirit of 'respect and synergy' (2005: 15). At a time when destructive evaluations of others' work seem to be the norm, his clear invitation to criticize constructively and with respect, and to promote synergy, is outstanding.

\section{Differences across the geographical breadth of the discipline}

Burawoy informs us that he has discussed public sociology in 40 venues in seven countries: the USA, England, Canada, Norway, Taiwan, Lebanon, and South Africa (2005: 5). However, it is not clear who his intended audience is. His vision of sociology is evidently directed to his American colleagues but at times he refers to the practice of sociology everywhere. Thus, taking into account the geographical breath of the discipline, I will draw attention to two aspects of Burawoy's arguments that would be inaccurate if they were directed to the international community of sociologists: the division of sociological labour or 'functional differentiation' among the four sociologies; and the nature of the friction among them. The first of these two aspects is the most important. 
Addressing the community of American sociologists in his Thesis $\mathrm{V}$, Burawoy points to a small elite of sociologists who, by virtue of their academic positions in top university departments that facilitate 'multiple locations', do work that straddles two or more of the four sociologies. The bulk of the sociology community, he states, work within one of the four sociologies 'at a time' (2005: 13-14). The sense conveyed by his analysis of the American data is that sociologists tend to find their niche in only one of the four sociologies at a time. Apparently the same general trend is observed in the UK. ${ }^{2}$ I would argue that, in general, all the four sociologies are alive and well in the international sphere but the distinct division of labour identified by Burawoy among professional, policy, public and critical sociologies for most sociologists in the USA, does not necessarily occur in other countries. I would suggest that sociologists with a doctoral degree working in Asia, Africa, and Latin America, tend to work on two, three, or all the four sociologies concurrently. Performing multiple roles concurrently is a typical situation rather than a unique feature of small elites within the discipline. There are many reasons for this, but among the most important is the influence of the socio-economic context within which sociologists in those world regions perform their roles.

Their situation is better understood using Earl Rubington and Martin S. Weinberg's (2003: 361) pertinent perspective on sociologists' dual mandate and the roles they play. In their view, sociologists have 'the dual mandate... to solve social problems as well as to develop sociology as a discipline'. ${ }^{3}$ Accordingly, they see sociologists playing four roles: 'theorist, researcher, applier, and critic'. Two of these roles, theorist and researcher, focus 'on developing sociology as a discipline' (2003: 361) and may be seen as the equivalent of Burawoy's professional sociology. The role of 'applier' could fit Burawoy's policy sociology, but Rubington and Weinberg have a wider vision of the application of sociology to policy. In their view, 'For appliers and critics, sociology should work permanently on behalf of society. Appliers draw on the implications of a given sociological theory in order to propose solutions for specific social problems' (2003: 361). In contrast to this definition of appliers inspired by the dual mandate principle, Burawoy defines policy sociology more narrowly as

sociology in the service of a goal defined by a client. Policy sociology's raison d'etre is to provide solutions to problems that are presented to us, or to legitimate solutions that have already been reached. (2005: 9)

The dearth of comprehensive information prevents a detailed portrait of the typical division of labour among sociologists in Latin America, Africa, and Asia. But a tentative sketch of the multiple-roles situation may be drawn based on direct observation, anecdotal data, and some country studies. ${ }^{4}$ The number of sociologists with doctoral degrees in these countries is smaller than in the USA, the UK or some other European countries. In addition to the small 
size of the local sociological community, their main source of employment is usually in universities, as teachers and researchers. These dual activities are an incentive and often an imperative to combine knowledge transmission with critical analysis as sociologists bring to their students' attention socioeconomic, cultural, religious, and other pressures of everyday life in their countries. More often than not, there is a sense of commitment to the dual mandate of sociology, primarily directed at the analysis of local or national social problems and the growth of the discipline in their country. Hence, it is not at all unusual to be a theorist and/or researcher and critic at the same time. Or, put in terms of Burawoy's four sociologies, sociologists become engaged in professional sociology and critical sociology while performing their main occupation as university teachers.

But these are not their only roles. The expertise of professional sociologists in academia has been and is in increasing demand by governmental and nongovernmental organizations in many Latin American, African, and Asian countries over the past two decades. This demand opens space for professional sociologists to apply their expertise to social problems and, more specifically, to pressing policy-relevant issues in their own societies. The struggles and crises of local communities they study often lead sociologists to engage different publics and, if they do not initiate public dialogue on their own, it is common for the local press and other mass media to bring sociological research findings and their authors to public attention.

This pressure to attend to a multiplicity of roles and to perform well as professional, policy, public and/or critical sociologists, may ease if and when the critical mass of $\mathrm{PhD}$ sociologists increases and the structural opportunities for the practice of sociology expand along the lines of the development of the discipline in North America and Western Europe. Meanwhile, sociologists in Asia, Africa, and Latin America continue working concurrently on piles of teaching notes and syllabi, research protocols, consultancy papers, and requests for interviews by newspapers or TV stations, among other matters.

The second aspect of Burawoy's arguments that would be inaccurate if it were directed to sociologists in Asia, Africa or Latin America, is the nature of the friction among the four sociologies. In his Thesis IV, Burawoy argues that the internal complexity of the discipline leads to its 'functional differentiation' into four different faces of Sociology: professional, policy, public and critical sociologies; while sharing moments, these four areas 'may not be in harmony with each other' (2005: 11-13). The friction he sees among the four sociologies tend to be less pronounced and more likely between two 'camps': critical sociology on the one side and the other three sociologies on the other side. Another version of the friction is the attempts by some critical sociologists to bring their message to various publics as activists.

Sociologists located beyond North America and Western Europe, as suggested earlier, face the same pressures and conflicts but, as they typically 
perform multiple roles, the frictions take a different modality. Sociologists engaged exclusively in critical sociology tend to emulate their American and European counterparts' in their disapproving views of professional and policy sociology. In general, they constitute a small group while most sociologists are busy attending to professional, policy, public, and critical aspects of the discipline.

In conclusion, Michael Burawoy has challenged us to think constructively and critically about sociology. His call for a shared ethos is timely and welcome. I have taken this opportunity to appeal for the discussion of his ideas in the context of the geographical breadth of our discipline.

(Date accepted: June 2005)

\section{Notes}

1. Let us say that the geographical breadth of the discipline comprises two roughly delineated spatial spheres of sociological work: the sphere comprising North America and Europe (and possibly Australia and New Zealand), and the international sphere comprising the rest of the world. The greater part of sociological literature in North America and Europe focuses on work within their own sphere. Sociological work conducted in the international sphere typically encompasses literature from both spheres. The geographical breadth of the discipline is well illustrated in analytical reviews of sociological research such as Bottomore, Nowak, and Sokolowska (1982); and Quah and Sales (2000).

2. According to Lauder, Brown and Halsey (2004), Johnson (2004), Davis (2004), and Wiles (2004), policy-relevant sociological research and public sociology in the UK have not received sufficient attention. But other British commentators disagree (Marris, 1990; Hammersley, 2004) and the there is a wealth of policy-relevant sociolog- ical literature. Examples of the latter are Liska and Messner (1999), Rubington and Weinberg (2003), and Hachen (2001).

3. Rubington and Weinberg are of course not the only ones highlighting this aspect. For example, the dual mandate of sociology is also implied by Ritzer and Goodman (2004:6) in two of the three criteria that classical theories must meet: 'theories must have a wide range of application' and 'must deal with centrally important social issues'. Their third criterion is that theories 'must have stood up well under the test of time'.

4. Some examples of multiple roles performed across the four sociologies are the study of family sociologists in Asia (Quah, 1993); the discussion of sociology in selected countries in Latin America (Briceno-Leon and Sonntag, 1998); and in Indonesia (White, 2005; Game-Rochman and Rochman, 2005). Illustrations of the considerable number of professional sociological research in Japan that is policy-relevant are the studies by Kanai and Wakabayashi (2004); and Izuhara (2004).

\section{Bibliography}

Bottomore, T., Nowak, S., and Sokolowska, M. (eds) 1982 Sociology: The State of the Art, London: Sage Publications.
Briceno-Leon, R. and Sonntag, H.R. (eds) 1998 Sociology in Latin America, Madrid: ISA. 
Burawoy, Michael 2005 '2004 ASA Presidential Address - For Public Sociology', American Sociological Review 70 (February): 4-28.

Davis, P. 2004 'Sociology and Policy Science: Just in Time?', British Journal of Sociology 55(3): 447-50.

Game-Rochman, M. and Rochman, A. 2005 'Inclusion and Exclusion: NGOs and Critical Social Knowledge', in V.R. Hadiz and D. Dhakidae (eds) Social Science and Power in Indonesia, Jakarta and Singapore: Equinox and ISEAS.

Hachen, D.S. Jr 2001 Sociology in Action. Cases for Critical and Sociological Thinking, London: Sage.

Hammersley, M. 2004 A New Political Arithmetic to Make Sociology Useful? Comments on Debate', British Journal of Sociology 55(3): 439-46.

Izuhara, M. 2004 "Negotiating Family Support? The "Generation Contract" Between Long-Term Care and Inheritance', Journal of Social Policy 33(4) (October): 649-65.

Johnson, P. 2004 'Making Social Science Useful', British Journal of Sociology, 55(1): 23-30.

Kanai, A. and Wakabayashi, M. 2004 'Effects of Economic Environmental Changes on Job Demands and Workaholism in Japan', Journal of Organizational Change 17(5): 537-48.

Lauder, H., Brown, P. and Halsey, A.H. 2004 'Sociology and Political Arithmetic - Some Principles of a New Policy Science', British Journal of Sociology 55(1): 3-22.

Lee, A.M. 1976 'Sociology for Whom?', American Sociological Review 41: 925-36.

Liska, A.E. and Messner, S.E. 1999 Perspectives on Crime and Deviance, 3rd Edition, Upper Saddle River, NJ: Prentice-Hall.
Lynd, R. 1939 Knowledge for What? The Place of Social Sciences in American Culture, Princeton, NJ: Princeton University Press.

Marris, P. 1990 'Witnesses, Engineers or Storytellers? Roles of Sociologists in Social Policy', in Herbert Gans (ed.) Sociology in America, Newbury Park, CA: Sag.

Quah, S.R. (ed.) 1993 Asian Sociologists at Work, Current Sociology 41(1) (Spring).

Quah, S.R. and Sales, A. (eds) 2000 International Handbook of Sociology, London: Sage.

Ritzer, G. 1975 Sociology. A Multiple Paradigm Science. Boston: Allyn and Bacon.

Ritzer, G. (ed.) 1990 Frontiers of Sociological Theory. The New Syntheses, New York: Columbia University Press.

Ritzer G. and Goodman, D.J. 2004 Classical Sociological Theory, 4th Edition, Boston: McGraw-Hill.

Rubington, E. and Weinberg, M.S. (eds) 2003 The Study of Social Problems. Seven Perspectives, 6th Edition, New York: Oxford University Press.

Smelser, N.J. 1998 'The Rational and the Ambivalent in the Social Sciences', American Sociological Review 63 (February): 1-16.

White, B. 2005 'Between Apologia and Critical Discourse: Agrarian Transitions and Scholarly Engagement in Indonesia', in V.R. Hadiz and D. Dhakidae (eds) Social Science and Power in Indonesia, Jakarta and Singapore: Equinox and ISEAS.

Wiles, P. 2004 'Debate, Policy and Sociology', British Journal of Sociology 55(1): 31-4.

Wiley, N. 1990 'The History and Politics of Recent Sociological Theory', in G. Ritzer (ed.) Frontiers of Sociological Theory. The New Syntheses, New York: Columbia University Press. 